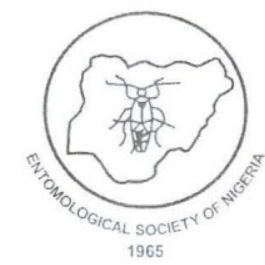

\title{
Activity Pattern and Distribution of African Invader Fly, Bactrocera invadens (Drew, Tsuruta and White) [Diptera: Tephritidae] in Ondo State, Southwestern Nigeria
}

\author{
*ADEBAyO, R.A., MUSTAPHA, M.O. AND OGUNFUMILAYO, A.O.' \\ Department of Crop, Soil and Pest Management, Federal University of Technology Akure, \\ Ondo State, Nigeria. \\ ${ }^{2}$ Nigeria Plant Quarantine Service, Post Surveillance Station, Moor Plantation, Ibadan, \\ Oyo State, Nigeria
}

Nig. J. Entomol. 33: 121-127(2017)

\begin{abstract}
African invader fly, Bactrocera invadens, is an invasive species and it has been reported as an economically important pest of fruits in Nigeria. The insect's pattern of activity was studied on mango (Mangifera indica Linn.) over a 2-week period in 2014 at the Federal University of Technology, Akure (FUTA) ( $5^{\circ} 14^{\prime \prime} \mathrm{E}$ and $\left.7^{\prime \prime} 30 \mathrm{~N}^{\prime \prime}\right)$, The population infesting three host plants, citrus (Citrus sinensis L.), mango, and pawpaw (Carica papaya Linn.) was assessed over 8-weeks at Adeyemi College of Education (ACE), Ondo, Rufus Giwa Polytechnic Owo (RUGIPO) ( $5^{\circ} 35^{\prime \prime}$ E and $\left.7^{\circ} 11 \mathrm{~N}^{\prime \prime}\right)$, and Adekunle Ajasin University, Akungba Akoko (AAUA) (5 44" E and $\left.7^{\circ} 28 \mathrm{~N}^{\prime \prime}\right)$. The flies were lured into locally-fabricated traps with methyleugenol pre-mixed with insecticide and catches were counted at 1100,1500 , and 1800 hours in the activity pattern study but at fortnightly intervals in infestation/distribution study. The experiments were laid in completely randomized design with three treatment replicates; trap catches were square root transformed before analysis of variance. Trap catches revealed that flies were prevalently active in the late morning and that location and host plant exerted significant influence. The highest trap catch was at AAUA (3866.67) followed by ACE (1726.99), and RUGIPO (1429.03). Mango was the most preferred host (4530.02), followed by citrus (1381.01), and pawpaw (1111.66). A total of seven thousand and twenty two (7022.69) flies were trapped at the three locations and on the hosts within the study period. It was concluded that $B$. invadens were most active in the late morning and were distributed in all the selected areas. Therefore, based on the results from the study, constant monitoring and trapping is recommended as a management option for the pestiferous $B$. invadens. Consequently, fly control strategy has to take cognisance of pest density variation by location, season, and host plant infested.
\end{abstract}

Keyword: Bactrocera invadens, activity pattern, distribution, trapping

\section{INTRODUCTION}

The production of fruits, particularly mango, citrus, pawpaw, apple, pineapple, and tomatoes, for local, urban and export markets is one of the fastest growing sector in African agriculture. However, access to international markets is hindered by infestation of tropical fiuit flies. Bactrocera invadens, is an exotic tropical fruit fly

*Corresponding author:

E-mail: raphael.adebayo $(a$ yahoo.com widely distributed in A frica and attacking diverse fruit and vegetable crops (Allwood and Drew, 1997: De Meyer et al., 2007: De Meyer et al., 2010; Drew et al., 2005; Ekesi and Billah, 2007; Lux et al., 2003; White and Elson-Harris, 1992). Characteristics that give it economic pest status include high mobility and dispersive powers, high reproductive rates, polyphagy, and top ranking on world list of insects of quarantine importance (Clarke et al., 2005; White, 2006). 
Females lay their eggs under the skin of fruits and larval development is completed inside the fruits which quickly rot (Ekesi and Billah, 2007). Host species attacked exceed 46 although mango is the most preferred (Goergen et al., 2011; Mwatawala et al., 2009). About $40 \%$ of the mangoes produced in Africa is lost to fruit flies whose infestation varies among countries and seasons from $5-100$ $\%$ (Drew et al., 2005). In Kenya, direct damage to mango by $B$. invadens ranges from $30 \%$ to $80 \%$ of the crop depending on the cultivar, locality and season(Ekesietal., 2006).

Fruit production and export is one of the fastest growing agricultural sectors in Africa, providing income and employment. Mangoes, citrus, pawpaw, apple, pineapple and tomatoes are among the commonest ones grown both for domestic, urban markets and for exports that target large markets in Europe and the Middle East. Besides export, is the changing dietary patterns leading to increased consumption of fruits (Lux et al., 2002). The presence of $B$. invadens has affected over twenty host plant which include tangelo, banana, plantain, strawberry guava, common guava, African peach, Ethiopian eggplant, apple, mango, avocado, tomato, African wild mango, bell pepper, chilli pepper, sour orange, sweet orange, grape, papaya, watermelon, lemon, tangerine etc. (De Meyer et al., 2007). Tropical fruit flies are major pests of fruits common in most area of the world and many species can exist with different host plant preferences and geographical distributions. The Bactrocera invadens, a fruit fly in the family Tephritidae, is among the most economically important pests of fruits and vegetables worldwide (Allwood and Drew, 1997; Lux et al., 2003). They constitute an important group of pest in many countries due to their potential to cause damage in fruits. They also restrict access to international markets of plant products that host them. Introduction of this new invasive fruit fly species, with high flying ability, high rate of reproduction and spread can establish easily in new environment or territories (Nwaneri, 2013). Since its first detection in 2003 on the East African Coastline (Drew et al., 2005), B. invadens has spread to over 28 African countries including the Comoros Islands and
Cape Verde (Ekesi and Billah, 2007; De Meyer et al., 2010). It has been recorded from 46 host plant species, although mango is the preferred host plant (Mwatawala et al., 2009; Goergen et al., 2011). Bactocera invadens is thought to be responsible for causing extensive economic losses to horticultural crops throughout Africa since its first report in 2003 (Lux et al., 2003). This is perhaps not surprising because, Asian fruit fly pests from the genus Bactrocera are regarded as among the most destructive insects of fruits and vegetables worldwide (White and Elson-Harris, 1992). With adult traits that can include high mobility and dispersive powers, high reproductive rates, and extreme polyphagy, Bactrocera species are well-documented invaders and rank high on quarantine lists world-wide (Clarke et al., 2005). It is uncertain exactly when and how $B$. invadens was introduced into Africa (Copeland et al., 2006). Females lay their eggs under the skin of fruit causing direct damage and the resulting larvae feed inside the fruit. Infested fruits quickly rot resulting in extensive losses (EkesiandBillah, 2007).

An assessment reveals that of the 1.9 million metric ton of mangoes produced in Africa annually, about $40 \%$ is lost due to fruit flies. Fruit infestation rates vary among countries and seasons, ranging from $5 \%$ to $100 \%$ (Drew et al., 2005). This pest has been reported to cause $15-50$ $\%$ yield losses in mango and some other fruit crops in some African countries (Vayssieres et al., 2005). In Kenya, direct damage to mango due to $B$. invadens ranged from $30 \%$ to $80 \%$ of the crop depending on the cultivar, locality and season (Ekesi etal., 2006).

The biology of Bactrocera complexes vary from one species to another. They undergo complete metamorphosis. Temperature, humidity, rainfall and other eco-climate factors affect the life cycle of $B$. invadens. Females lay their eggs under the skin of fruit causing direct damage and the resulting larvae feed inside the fruit. Infested fruits quickly rot resulting in extensive losses (Ekesi and Billah, 2007). Bactocera invadens is multivotine and reproduce with an average life span of about three months (White, 2006). Infestation of $B$. invadens has been reported in Nigeria and the spread of the insect monitored in 


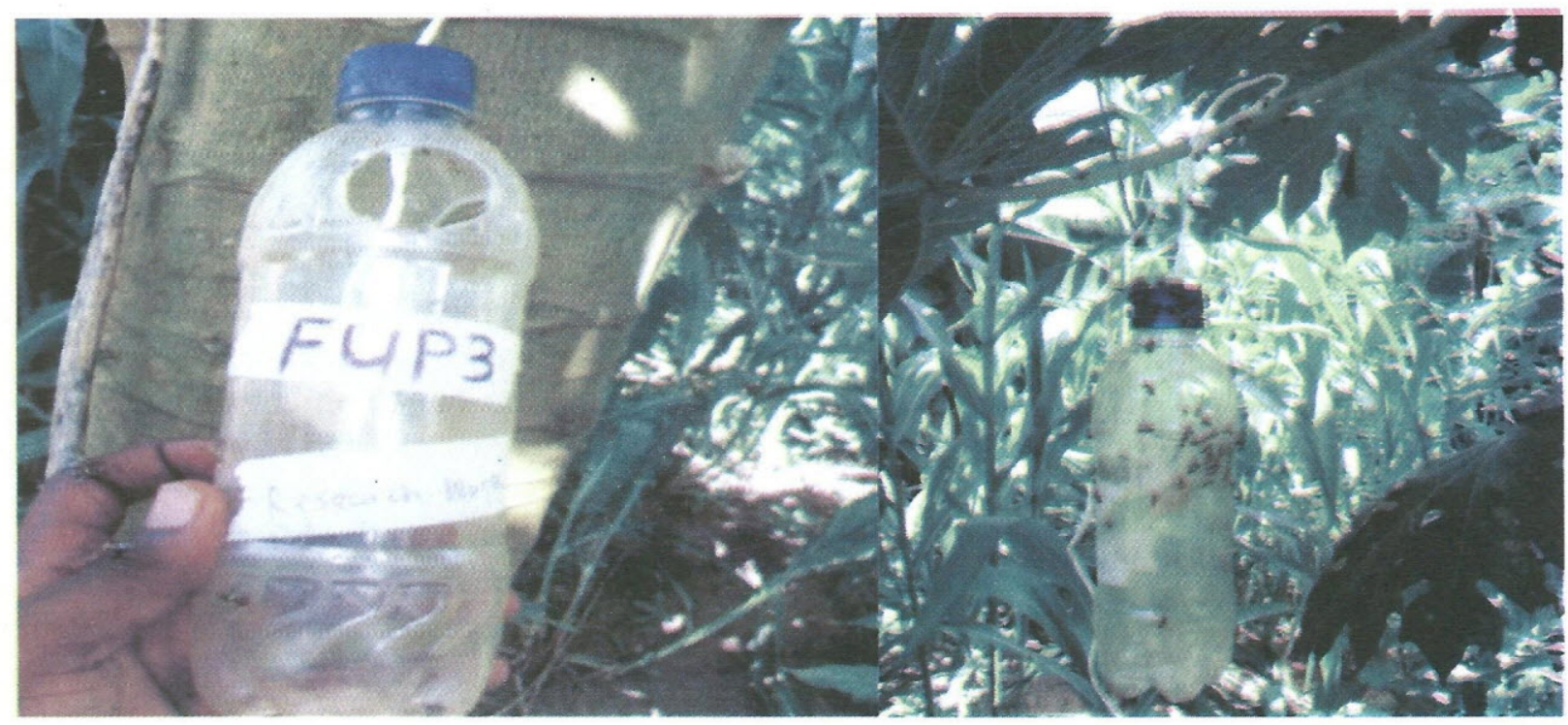

Figure 1: Fabricated bottle traps

various parts of the country (Adebayo and Akinbola, 2014: Asawalam et al., 2009; Umeh et al., 2004; 2008). Fruit flies identified on citrus belonged to the genera Bactrocera, Ceratitis, Dacus and Trirhithrum. While higher fruit fly diversity was observed in Edo, Ogun and Oyo States in the rainforest ecological zone, relatively higher populations of major genera (Bactrocera and Ceratitis) were recorded in Benue and Kaduna States in the Guinea savanna ecological

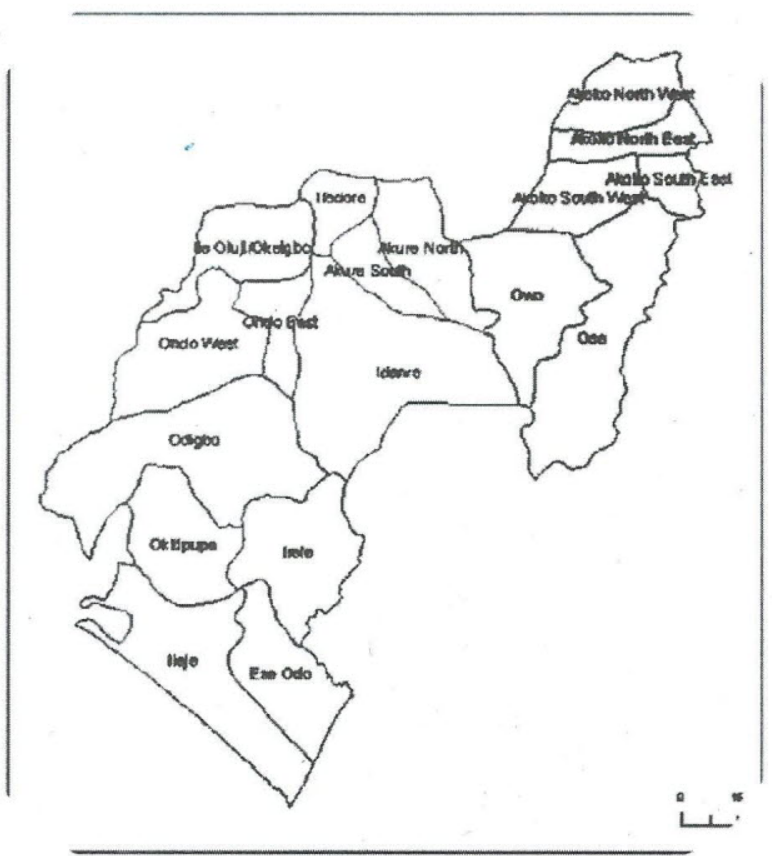

Figure 2: The map of Ondo State showing Ondo West, Akure South, Owo and Akoko North East Local Government Areas as the study locations zone (Umeh et al., 2008). They also reported a $27 \%$ attack of fruits in Ondo State. However, only citrus was surveyed in their study. Observations have shown that, in most parts of Nigeria, fruit fly damage occurs at all times when fruits are set, whereas damage by the fruit piercing moths varies from one year to another (Umeh, unpublished data). Fruit fly populations can be said to have attained a numerical stability over a long period (Eguagie and Udensi, 1989) and are of economic significance at a particular phenological stage of the plant (usually during the fruiting season). In severe infestation, as high as $70 \%$ of set fruits may be lost with the combined attack of these insects (Babatola, 1985).

Therefore, the present study investigated the activity pattern and distribution of $B$. invadens in four Local Government Areas of Ondo State, South-western Nigeria, on mango, citrus and pawpaw.

\section{MATERIALSAND METHODS}

\section{Study Sites}

Figure 2 shows the sites used for the study. To investigate the activity pattern of the fly over a 2 week period in 2014, mango at the crop type museum, Obekekere, of the Federal University of Technology Akure (FUTA), Akure South Local Government Area was used. For the distribution of $B$. invadens in Ondo State, biweekly trapping of the fly on citrus, mango, and 
pawpaw in the campuses of Adeyemi College of Education (ACE), Ondo-West Local Government Area; Rufus Giwa Polytechnic Owo (RUGIPO), Owo Local Government Area, and Adekunle Ajasin University Akungba (AAUA), Akoko North-East Local Government Area was carried out over a period of eight weeks.

At FUTA, treatment consisted of trap catches of fruit flies at 1100, 1500, and 1800 hours on mango trees spaced $50 \mathrm{~m}$ apart. Experimental set up at ACE, RUGIPO, and AAUA were similar but utilized three host crops and the trap catches were collected fortnightly. The plastic bottle traps used were fabricated according to the design of Billah et al., (2005) [Fig. 1] and baited with methyl Eugenol (4-allyl-1, 2-dimethoxybenzen, AgriMat ${ }^{\circledR}$, England) pre-mixed with insecticide Cypermethrin $\left(\right.$ Plan $^{\mathrm{R}}$ or $\mathrm{Akape}^{\mathrm{R}}$ ) in ratio 4:1. Flies collected were identified using the morphological key of Billah et al., (2005).

\section{Data Analysis}

Data on trapped flies were square root transformed and subjected to Analysis of Variance using Statistical Package for Social
Science (SPSS), version 16.0. Means were separated using Tukey's test at $95 \%$ probability.

\section{RESULTS}

Table 1 shows that B. invadens infestation occurred all-day long but activity was generally more prevalent in the late morning. Whereas in week 1 only, the late morning and evening collections differed significantly, in week 2 , the differences of each of the afternoon and evening collection was significantly different from that of the late morning collection. B. invadens was found on all host plants examined and at all locations selected for the study of distribution. Across hosts and locations, 7,022 flies were trapped. Numbers trapped were preponderantly higher at AAUA (2.2- and 3.0-fold more than at ACE and RUGIPO, respectively) and on mango (3.6-and 3.9-fold more than on citrus and pawpaw, respectively) (Table 2). The preference for mango was consistently demonstrated by the significance of the weekly trap catches at AAUA (Table 3), and those of weeks 4 and 6 at ACE (Table 3). At RUGIPO, the weekly trap catch differences among hosts were due to random variation (Table 3 ).

Table 1: Comparison of trap catches on mango at different times of the day in FUT, Akure

\begin{tabular}{cll}
\hline Trap Collection Time & \multicolumn{2}{c}{ Number of Flies Trapped At Week ${ }^{*}$} \\
\cline { 2 - 3 } & \multicolumn{1}{c}{1} & \multicolumn{1}{c}{2} \\
\cline { 2 - 3 } Morning $(11.00 \mathrm{am})$ & $2.87 \mathrm{a}(8.95)$ & $3.70 \mathrm{a}(14.10)$ \\
Afternoon $(3.00 \mathrm{pm})$ & $2.34 \mathrm{ab}(6.24)$ & $2.01 \mathrm{~b}(4.43)$ \\
Evening $(6.00 \mathrm{pm})$ & $2.22 \mathrm{~b}(5.29)$ & $2.30 \mathrm{~b}(5.14)$ \\
\hline
\end{tabular}

*Means followed by the same letter within a column are not significantly different $(\mathrm{P}>0.05)$ using Tukey's test; untransformed data are presented in parentheses.

Table 2: Comparison of trap catches by location and host plant for 8 weeks

\begin{tabular}{lllll}
\hline & \multicolumn{4}{c}{ No of trapped flies } \\
\cline { 2 - 5 } Location * & Citrus & Pawpaw & Mango & Total \\
\hline AAUA & $39.71 \mathrm{~b}(472.34)$ & $41.42 \mathrm{~b}(439.66)$ & $117.92 \mathrm{a}(2954.67)$ & $(3866.67)$ \\
ACE & $37.90 \mathrm{~b}(372.33)$ & $38.48 \mathrm{~b}(438.66)$ & $57.29 \mathrm{a}(916.00)$ & $(1726.99)$ \\
RUGIPO & $46.00 \mathrm{a}(536.34)$ & $30.12 \mathrm{~b}(233.34)$ & $49.48 \mathrm{~b}(659.35)$ & $(1429.03)$ \\
\hline Total & $(1381.01)$ & $(1111.66)$ & $(4530.02)$ & $(7022.69)$ \\
\hline
\end{tabular}

*Means followed by the same letter within a column were not significantly different $(\mathrm{P}>0.05)$ using Tukey's test; untransformed data were presented in parenthesis. 
Table 3: Weekly trap catches on three host fruits at Adeyemi Collge of Education, Ondo (ACE), Rufus Giwa Poytechnic Owo (RUGIPO) and Adekunle Ajasin University, Akungba (AAUA)

No of flies at indicated Week

\begin{tabular}{|c|c|c|c|c|}
\hline \multirow[b]{2}{*}{$\begin{array}{l}\text { ACE } \\
\text { Host }\end{array}$} & \multicolumn{3}{|c|}{ No of flies at indicated Week } & \multirow[b]{2}{*}{8} \\
\hline & 2 & 4 & 5 & \\
\hline Mango & $11.66(155.67)$ & $9.94 \mathrm{a}(100.00)$ & $19.17 \mathrm{a}(367.33)$ & $16.52(293.00)$ \\
\hline Citrus & $7.62(58.67)$ & $7.79 \mathrm{ab}(60.00)$ & $11.10 \mathrm{~b}(123.33)$ & $11.39(130.33)$ \\
\hline Pawpaw & $\begin{array}{l}6.35(39.33) \\
\text { NS }\end{array}$ & $6.07 \mathrm{~b}(38.00)$ & $15.54 \mathrm{ab}(246.00)$ & $\begin{array}{l}10.52(115.33) \\
\text { NS }\end{array}$ \\
\hline $\begin{array}{l}\text { RUGIPO } \\
\text { Host }\end{array}$ & & & & \\
\hline Mango & $11.39(130.33)$ & $11.76(159.69)$ & $12.80(181.33)$ & $13.53(188.00)$ \\
\hline Citrus & $11.52(133.67)$ & $11.18(126.00)$ & $11.49(132.67)$ & $11.81(144.00)$ \\
\hline Pawpaw & $\begin{array}{l}8.13(67.33) \\
\text { NS* }\end{array}$ & $\begin{array}{l}5.69(31.67) \\
\text { NS }\end{array}$ & $\begin{array}{l}7.42(54.67) \\
\text { NS }\end{array}$ & $\begin{array}{l}8.88(79.67) \\
\text { NS }\end{array}$ \\
\hline
\end{tabular}

AAUA

Host

Mango

23.86a (569.67)

$35.04 \mathrm{a}(629.00)$

$27.58 \mathrm{a}(764.00)$

$31.44 \mathrm{a}(992.00)$

Citrus

$9.03 \mathrm{~b}(86.67)$

$10.44 \mathrm{~b}(133.67)$

$10.84 \mathrm{~b}(134.00)$

$9.40 \mathrm{~b}(118.00)$

Pawpaw

$11.09 b(123.33)$

$9.77 b(95.00)$

$10.15 \mathrm{~b}(113.33)$

$10.41 \mathrm{~b}(108.00)$

*Means followed by the same letter within a column in the same location are not significantly different $(\mathrm{P}>0.05)$ using Tukey's test; untransformed data are presented in parenthesis.

\section{. DISCUSSION}

$B$. invadens was detected and trapped at all study sites and on the three fruit hosts confirming the establishment of the species in Ondo State as previously reported by Adebayo and Akinbola (2014). The numbers trapped varied with location and host plant as a result of biotic and abiotic factors. Previous studies had shown the influence of predatory tailor ants, Oecophylla sp., noise pollution, moist humid environment on fly population (Aruna et al., 2009; Adebayo and Akinbola, 2014). The preference of $B$. invadens for mango is in agreement with the findings of Adebayo and Akinbola (2014), Aruna et al. (2009), Ekesi et al. (2006), and Utomi (2006). Infestation of the other hosts confirmed the wide host range of this fly (Allwood and Drew, 1997; Lux et al., 2003). The study substantiated the reliability of locally-fabricated, methyl eugenol-baited traps, previously used by Asawalam et al. (2009) and Adebayo and Akinbola (2014) as tool for surveillance of $B$. invadens. Though
Umeh et al. (2008) used different traps and bait, the flies were attracted and detected. The presence of the fly in all the locations further confirmed the works of Umeh et al. (2004; 2008). The present study however, showed that several factors were responsible for the presence of the fly in the locations. The nature of the location of the orchard and human disturbances seemed to greatly influence their presence. The highest fly population caught on mango in all the locations showed that it is the most parasitized by the fly.

\section{CONCLUSION}

Establishment of B.invadens in Ondo State has been affirmed using locally-constructed, methyl eugenol-baited traps. The fly's prevalent activity period is late morning. Mango was the most preferred of the host tested. The distribution of the fly in the locations at the Local Government Areas was influenced by the nature of the orchard and human disturbances. 


\section{REFERENCES}

Adebayo, R.A. and Akinbola, S.T. (2014). Distribution pattern and host preference of African invader fly, Bactocera invadens (Drew, Tsuruta White) (Diptera: Tephritidae) in Akure and its environs Molecular Entomology, 5(7):1-6.

Allwood, A.J. and Drew, R.A.I. (1997). Control strategies for fruit flies (family Tephritidae) in the South Pacific. In: Allwood; A.J., Drew, R.A.I. (Eds.), Management of Fruit Flies in the Pacific (Allwood, A.J. and Drew, R.A.I. eds.), pp. 171-178. Proceedings No. 76 of Australian Centre for International Agricultural Research

Aruna, M., Jan-Hendrik, V. and Vaughan, H. (2009). Bactrocera invadens Drew Tsuruta and White. The African Invader fly. Action Plan. 3(5): 8-9.

Asawalam, E. F., Ekesi, S. and Ibeabuchi, $O$. K. (2009).Monitoring population of the African invader fly, Bactrocera invadens (Drew, Tsuruta \& White) [Diptera: Tephritidae], with methyl eugenol and nulure on Citrus in IkwuanoLocalGovernmentArea ofAbiaState, Nigeria. Nigerian Journal of Entomology, 26: 47-50.

Babatola, J.O.(1985). Diseases and pests of fruits and their control, in: Proc. National Fruit Production Workshop, FACUNIHORT, Ibadan, Nigeria, pp. 120-132.

Billah, M., Wilson, D.D. and Cobblah, M.A. (2005). Detection by the preliminary survey of the new Bactrocera invasive fruit fly species in Ghana. Paper Presented at the 24th Biennial Conference of the Ghana Science Association.

Clarke, A. R., Armstrong, K. F., Carmichael, A.E., Milne, J. R., Raghu, S., Roderick, G. K. and Yates, D. K.(2005). Invasive phytophagous pests arising through a recent tropical evolutionary radiation: The Bactroceradorsalis complex of fruit flies. Annual Review of Entomology, 50: 293319.

Copeland, R.S., Wharton, R.A., Luke, Q. and De Meyer, M. (2006). Indigenous hosts of
Ceratitis capitata (Diptera: Tephritidae) in Kenya. Annals of Entomological Society of America, 95(6): 672-694.

De Meyer, M., Mohamed, S. and White, I.M. (2007). Invasive fruit fly pests in Africa. Retrieved from:

http://www.africamuseum.be/fruitfly/Afro Asia.

De Meyer, M., Robertson, M., Mansell, M., Ekesi, S., Tsuruta, K., Mwaiko, W., Vayssières, J.-F., and Peterson, T. (2010). Ecological niche and potential geographic distribution of the invasive fruit fly Bactrocera invadens (Diptera, Tephritidae). Bulletin of Entomological Research. 100, 35-48.

Drew, R.A.I., Tsuruta, K. and White, I.M. (2005). A new species of pest fruit fly (Diptera: Tephritidae: Dacinae) from Sri Lanka and Africa. African Entomology, 13: 149-150.

Eguagie, W.E. and Udensi, N. (1989). Control of insect pests and diseases of citrus and mango in Nigeria, National Horticultural Research Institute (NIHORT), Tech. Bull., No. 5, Nigeria

Ekesi, S., Nderitu P.W. and Rwomushana I. (2006). Field infestation, life history and demographic parameters of the fruit fly Bactrocerainvadens (Diptera: Tephritidae) in Africa. Bulletin of Entomological Research 96:379-386.

Ekesi, S. and Billah, M.K. (2007). A Field Guide to the Management of Economically Important Tephritid Fruit Flies in Africa. ICIPE Science Press, ICIPE, Nairobi, Kenya.

Goergen, G., Vayssières, J.-F., Gnanvossou, D. and Tindo, M. (2011). Bactrocera invadens (Diptera: Tephritidae), a new invasive fruit fly pest for the afro-tropical region: host plant range and distribution in West and Central Africa. Environmental Entomology, 40: 844-854.

Mwatawala, M.W., De Meyer, M., Mkundi, R.H. and Maerere, A.P. (2009). Host range and distribution of fruit-infesting pestiferous fruit flies (Diptera, Tephritidae) in selected areas of Central Tanzania. 
Bulletin of Entomological Research,(6): 629-641.

Nwaneri, M.K.(2013). Fruit fly suppression in Nigeria. A keynote address presented at a workshop organized by the Nigeria Agricultural Quarantine Service (NAQS), Ibadan, Oyo State. July, 2013.4pp.

Lux, A.S., Ekesi, S., Dimbi, S., Mohamed, S and Billah, M. (2002). Mango-infesting fruit flies in Africa: Perspectives and limitations of biological approaches to their management In: Biological Control in IPM Systems in Africa (Neuenschwander, P.: Borgemeister, C. and Langewald, J. eds.), CAB International, UK. pp.277-293.

Lux, S.A., Copeland, R.S., White, I.M., Manrakhan, A. and Billah, M.K. (2003). A new invasive fruit fly species from the Bactrocera dorsalis (Hendel) group detected in East Africa. Insect Science and its Applications, 23(4):355-361.

Umeh, V. C., Garcia, L. E. and De Myer, M. (2008). Fruit flies of citrus in Nigeria: Species diversity, relative abundance and spread in major producing areas. Fruits, 63
(3): 145-153.

Umeh, V. C., Olaniyan, A. A., Ker, J. and Ander, J. (2004). Development of fruit fly control strategies for shall-holders in Nigeria. Fruits, 59 (4):265-274.

Utomi, C.I. (2006). The distribution, host range and natural enemies of the new invasive fruit fly Species, Bactrocera invadens (Diptera, Tephritidae), in South eastern Ghana. M.Phil. Thesis. University of Ghana, Legon. p. 50.

Vayssieres, J. F., Goergen, G., Lokossou, O., Dossa, P. and Akponon, C.(2005). A new Bactrocera species in Benin among mango fruit fly (Diptera: Tephritidae) species. Fruits, 60:371-377.

White, I.M. and Elson-Harris, M.M. (1992). Fruit flies of Economic Significance: Their Identification and Bionomics. CAB International, Wallingford, UK.601pp.

White, I.M. (2006). Taxonomy of the Dacina (Diptera: Tephritidae) of African and the Middle East. African Entomology Memoir 2: 10 .

*Adebayo, R.A., Mustapha, M.O. and Ogunfumilayo, A.O.'

Nigerian Journal of Entomology

Published by the Entomological Society of Nigeria

www.esn.org.ng

ISSN: 0331-0094

Volume 33, 2017

pp. 121-127

DOI:10.36108/NJE/7102/33(0141)

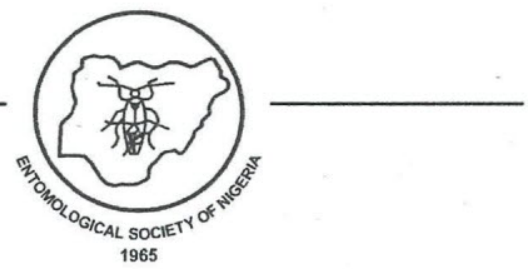

